\title{
Os clientes e os enfermeiros: construção de uma relação
}

\author{
PATIENTS AND NURSES: BUILDINGARELATIONSHIP
}

LOS CLIENTES Y LOS ENFERMEROS: CONSTRUCCIÓN DE UNA RELACIÓN

\author{
Manuel José Lopes ${ }^{1}$
}

1 Enfermeiro. Professor coordenador e vice-presidente da Escola Superior de Enfermagem S. João de Deus - Evora.

Especialista em Enfermagem de Saúde Mental e Psiquiátrica.Mestre em Ciências de Enfermagem pela Universidade Católica de Lisboa.Doutorando em Ciências de Enfermagem no Instituto de Ciências Biomédicas Abel Salazar Porto.

manueljlopes@netcabo.pt

\section{RESUMO}

Os objetivos deste estudo foram compreender a natureza da interação entre enfermeiros e doentes oncológicos submetidos à quimioterapia, num hospitaldia, e construir uma teoria de médio alcance. Os dados foram obtidos por meio de entrevistas narrativas com cinco enfermeiras, dez doentes e familiares; grupo focal com as enfermeiras; dez entrevistas de admissão, feitas pelas enfermeiras, e 60 dias de observações. A metodologia que guiou o processo de coleta e de análise dos dados, foi a Grounded Theory. Os resultados apresentam a teoria de médio alcance construída, cuja natureza é constituída por dois componentes: "Processo de avaliação diagnóstica" - coleta de novos dados, reavaliação do processo e acompanhamento da prestação de cuidados e "Processo de intervenção terapêutica de enfermagem" - gestão simultânea de sentimentos e informação. $\mathrm{Na}$ teoria desenvolvida, o componente da dimensão relacional da experiência consiste num processo seqüencial em três fases: Início, corpo e fim da relação.

\section{DESCRITORES}

Relações enfermeiro-paciente.

Comportamento de ajuda.

Cuidados de enfermagem.

Enfermagem oncológica.

\begin{abstract}
The purposes of this study were to understand the nature of the interaction between nurses and cancer patients undergoing chemotherapy in a day hospital and to generate a nurse-patient relationship middle range theory. Grounded Theory methodology was used to guide data collection and analysis. Data collection strategies were: narrative interviews conducted with 5 nurses and 10 patients and relatives; a focus group with the nurses; 10 admission interviews carried out by the nurses; and a 60-day observation period. The findings describe the middle range theory that was built, whose nature is comprised of two components: "Process of diagnostic evaluation" - collection of new data, reevaluation of the process and monitoring of caring procedures -; and "Process of nursing therapeutic intervention" - the simultaneous management of feelings and information. In the theory that was developed, the component of the relational di-mension of the experience con-sists of a 3-phase sequential process: beginning, body and end of the relationship.
\end{abstract}

\section{KEY WORDS}

Nurse-patient relations.

Helping behavior.

Nursing care.

Oncologic nursing.

\section{RESUMEN}

Los objetivos de este estudio fueron comprender la naturaleza de la interacción entre enfermeros y enfermos oncológicos sometidos a la quimioterapia, en un hospital de dia, y construir una teoría de medio alcance. Los datos fueron obtenidos por medio de entrevistas narrativas a cinco enfermeras, diez enfermos y familiares; grupo focal con las enfermeras; diez entrevistas de admisión, realizadas por las enfermeras, y 60 días de observaciones. La metodología que guió el proceso de recolección y análisis de los datos, fue la Grounded Theory. Los resulta-dos presentan la teoría de medio alcance construída, cuya natura-leza está constituída por dos componentes: "Proceso de evaluación diagnóstica" - recolección de nuevos datos, reevaluación del proceso y acompañamiento de la prestación de cuidados y "Proceso de intervención terapéutica de enfermería" - gestión simultánea de sentimientos e información. En la teoría desarrollada, el componente de la dimensión relacional de la experiencia consiste en un proceso secuencial en tres fases: Inicio, cuerpo y fin de la relación.

\section{DESCRIPTORES}

Relaciones enfermeiro-paciente. Conducta de ayuda.

Atención de enfermería. Enfermería oncológica. 


\section{INTRODUÇÃO}

O meu interesse pela relação como forma de intervenção terapêutica, em prol da ajuda ao outro, existe desde há muito tempo. Este interesse radica em convicções pessoais e profissionais. Enquanto ser humano, sei o que significa sentir a presença de outrem em momentos de grande perturbação. Esse outrem pode até ser um estranho, contudo, se a sua presença é sentida como autêntica, os seus efeitos são notáveis. No contexto profissional, aprendi com os doentes que o que está em causa numa situação de doença, não é apenas, nem principalmente, um processo fisiopatológico, mas antes e sobretudo, uma experiência humana. Enquanto tal, pode ser ou não muito enriquecedora dependendo não só de quem a vive, mas também, de com quem a vive. Aqui, podem assumir papel de destaque os técnicos de saúde. Foi também através do contacto com estes, principalmente com os enfermeiros, que aprendi o que não vinha nos livros, ou seja, que a arte da presença pode fazer a diferença no contexto da experiência humana de doença. Compreende-se assim que Heron ${ }^{(1)}$, ao referir-se aos atributos essenciais de um terapeuta, o faça de tal forma que parece que, em simultâneo, se refere a características intrínsecas ao ser humano. Ou seja, a combinação da preocupação, empatia, pré-consciência, facilitação e genuinidade, sendo atributos de um terapeuta, são simultaneamente patrimônio da espécie humana. Apesar de assim ser subsistem as questões: como fazer emergir este patrimônio? Como pô-lo eficazmente ao serviço do outro? Como profissionalizá-lo?

Estas questões ganham particular acuidade no caso da enfermagem, porque é o enfermeiro a pessoa que mais tempo passa junto do doente; e porque, dado o estádio do desenvolvimento do conhecimento em enfermagem, esse patrimônio pode não estar ainda organizado. Por isso e no contexto dos meus papéis de docente, investigador e prestador de cuidados, lancei-me na procura de respostas. Tenho percorrido três vias: a formação, com o estudo criterioso das teorias relacionais existentes; o desenvolvimento de competências relacionais, através da prestação de cuidados; e a investigação e reflexão.

Através da formação percebi que, na enfermagem, a relação enquanto instrumento terapêutico, tem sido objeto de interesse desde há imensos anos. Neste percurso, o papel relacional do enfermeiro aparece, pela primeira vez, caracterizado e definido sem ambiguidade e numa base científi$\mathrm{ca}^{(2)}$. Após esta, surgiram diversas outras estruturas conceituais ${ }^{(3-4)}$, as quais não apresentam dife- renças profundas relativamente à proposta por Peplau e tal como esta, estão particularmente vocacionadas para contextos psiquiátricos. O conjunto destes contributos teóricos foi agrupado ${ }^{(5)}$ sob a designação de "escola da interação", cujos elementos caracterizadores radicam nas teorias que a influenciam (teoria sistêmica, fenomenologia e o existencialismo) e no modo como definem a pessoa, a saúde, o ambiente, os cuidados de enfermagem e o processo de cuidados ${ }^{(5-6)}$. Todavia, a problemática da relação enquanto instrumento terapêutico está também presente nas restantes teorias de enfermagem, independentemente da escola de pensamento em que se integrem, sendo particularmente evidente em algumas teorias ${ }^{(7-8)}$. Nos anos mais recentes, apareceram algumas teorizações, sobretudo de origem francesa, sobre a intervenção relacional terapêutica e não limitadas a contextos psiquiátricos ${ }^{(9-10)}$.

Paralelamente, incrementei um projeto de intervenção relacional terapêutica, dirigido a doentes oncológicos sujeitos a cirurgia mutilante, através do qual pude desenvolver as minhas competências relacionais. A ação/reflexão associada a esta experiência, permitiu-me constatar, por um lado, que: os doentes manifestavam dificuldades vivenciais, resultantes da situação de doença oncológica e que se podem caracterizar, genericamente, como uma vivência de transição ${ }^{(11)}$ ou de crise ${ }^{(12)}$, ainda que com particularidades (crise reincidente, de desfecho imprevisível, com a qual é necessário aprender a viver). Por outro lado, percebi que a intervenção estritamente relacional era incompleta para as necessidades expressas pelos doentes. Por último, as situações com que me deparava exigiam o desenvolvimento de estratégias que, sendo eficazes, não as encontrava descritas na literatura. Com base nesta reflexão instalaram-se algumas dúvidas: Será que, no contexto da ação desenvolvemos estratégias e competências inovadoras de que não temos uma consciência plena? Como consciencializar e teorizar esse processo?

Estas dúvidas conduziram-me aos autores que, em áreas diversas, se têm dedicado ao estudo das competências desenvolvidas no contexto da ação ${ }^{(13-16)}$. Em todos estes trabalhos torna-se patente a defesa de uma epistemologia da prática. Esta consiste na perspectiva de que a prática é algo sempre diferente e mais complexo do que qualquer teoria pode captar. Trata-se assim de uma redefinição do conceito aristotélico de praxis, no sentido em que é proposto por alguns autores ${ }^{(17-18)}$.

Em resumo, o trabalho que aqui apresento resulta da conjugação de um tríptico de razões constituído pela: reflexão e análise da minha experiên-
Os clientes e os enfermeiros: construção de uma relação 
cia pessoal e profissional; constatação das características praxilógicas do saber em enfermagem; e necessidades expressas pelos doentes oncológicos. Propus-me assim desenvolver um estudo que me permitisse compreender, a natureza da relação entre os enfermeiros e os doentes oncológicos submetidos à quimioterapia num hospital-dia. Este estudo teve como objetivos: Compreender a natureza da interação entre os enfermeiros e os doentes oncológicos submetidos à quimioterapia num hospital-dia; Desenvolver uma teoria de médio alcance sobre a relação enfermeiro-doente; Contribuir para a construção da disciplina de enfermagem.

\section{OPÇÕES METODOLÓGICAS}

Face à natureza do problema e aos meus referenciais epistemológicos e disciplinares relativos à enfermagem, optei por desenvolver um estudo de natureza qualitativa. Fundamento a minha opção com autores como Morse et al ${ }^{(19)}$, Miguélez ${ }^{(20)}$ Olabuénaga ${ }^{(21)}$, entre outros. Dentre as diversas abordagens qualitativas possíveis optei pela grounded theory. Tal decisão baseia-se no facto de esta abordagem ser particularmente útil em situações de natureza psicossocial, organizacional, entre outras, que carecem de teorização e sobre as quais é necessário desenvolver o conhecimento, particularmente no que diz respeito ao seu processo e estrutura ${ }^{(22-23)}$.

\section{Desenvolvimento do estudo}

Para a escolha do local de realização do estudo foram usadas medidas reputacionais (a qualidade percebida da relação dos enfermeiros com os doentes e famílias) junto de diversos profissionais de saúde, de alguns clientes e de colegas professores. Procedi então ao pedido de autorização ao Conselho de Administração do hospital, o qual, após ter coletado os pareceres julgados convenientes junto às diversas entidades $\mathrm{e}$ órgãos, autorizou-me a realização do estudo. Após os contatos iniciais com os diversos atores do serviço, desenvolvi um estudo piloto, cujo objetivo foi, recolher os elementos necessários à tomada de decisões e delineamento de estratégias de investigação.

\section{Coleta de dados}

Na coleta de dados utilizei a entrevista e a observação. Dentre as diversas técnicas de entrevista possíveis, optei pela entrevista narrati$\mathrm{va}^{(24)}$. Foram previamente explicados aos entrevistados os objetivos do trabalho, o tratamento a que os dados iriam ser sujeitos, garantida a confidencialidade e solicitada autorização para a realização da entrevista e para a sua gravação em suporte magnético. Todas as enfermeiras (5) foram entrevistadas e fizeram o relato de um processo relacional, exceto uma que fez de dois e deu contribuições para um terceiro. Os doentes foram escolhidos tendo em consideração a sua capacidade de reflexão sobre o processo que estavam vivenciando ou tinham vivenciado (confirmada com as enfermeiras); estarem em momentos diferentes do processo de quimioterapia; pertencerem a diferentes grupos etários e gêneros; e terem diferentes tipos de experiências. Foram entrevistados 10 doentes e respectivo(s) familiar(es). Usei ainda o grupo focal ${ }^{(25)}$ como técnica de coleta de dados, em associação com as entrevistas narrativas feitas às enfermeiras e com o objetivo de procurar a sua interpretação dos resultados já alcançados. O grupo focal ocorreu em espaço próprio, teve a duração de cerca de duas horas, do mesmo foi feito registro em suporte magnético e nele estiveram presentes todas as enfermeiras.

Na observação e em coerência com as opções metodológicas assumidas, optei pelo posi-cionamento proposto pela escola dramatúrgica ${ }^{(26)}$, assumindo um papel de marginalidade face à situação e destacando-me da mesma de modo a interferir o menos possível. Com o objetivo de lhe conferir orientação e rigor, usei um roteiro, elaborado a partir do estudo piloto. Optei pelo sistema narrativo de registo de da$\operatorname{dos}^{(27)}$, o qual se caracteriza por: não ter categorias predeterminadas; centrar-se sobre o comportamento e sobre o seu significado em contexto; centrar-se sobre os comportamentos tal como eles ocorrem; plasmar-se em diários ou notas de trabalho de campo, as quais descrevem incidentes críticos ou anedóticos ocorridos num dado período; ter como objetivos a descrição pormenorizada dos fenômenos e a evolução dos processos. Assim, procedi preferencialmente à observação da interação enfermeira-doente, em contexto. Foi dada particular atenção à continuidade da interação. Assim, o número total de interações enfermeira-doente observadas em continuidade foi 55. Destas interações, 27 foram com doentes do sexo feminino e 28 com doentes do sexo masculino. A observação decorreu durante cerca de 60 dias, distribuídos ao longo de cinco meses. Integrado na observação, procedeu-se ainda à gravação, em suporte magnético, de 10 entrevistas de admissão efetuadas pelas enfermeiras aos doentes, no momento em que estes iniciavam o seu processo de quimioterapia. 
O uso de dados oriundos de fontes diversas (doentes e enfermeiras), bem como a utilização de diferentes técnicas de coleta de dados (entrevistas narrativas e observação), foi uma estratégia deliberada no sentido de conferir rigor aos dados obtidos $^{(28)}$.

\section{Organização e análise de dados}

A organização de dados iniciou-se simultaneamente à coleta e consistiu na redução a texto de dos dados. A análise de dados permitiu-me descobrir as categorias e as suas características, a relação destas com as subcategorias e com a categoria central e perceber a necessidade de coleta de novos dados, até à saturação teórica, a qual foi alcançada. Este processo desenvolveu-se por três fases distintas, embora intimamente interrelacionadas (codificação aberta, axial e seletiva) e permitiu a construção de uma estrutura conceitual coerente e baseada nos dados ${ }^{(22-24)}$.

$\mathrm{Na}$ análise de dados usei como critério de rigor, entre outros, um painel de "classificadores múltiplos" com o objetivo de aferirem as categorizações por mim desenvolvidas, considerando, a lógica interna de cada categoria; a relação entre as categorias e destas com as subcategorias; e a relação entre as categorias, considerando as diversas fontes.

\section{RESULTADOS}

Para melhor compreensão dos resultados interessa começar pela compreensão do contexto. Assim, o espaço físico caracterizava-se por ser novo, espaçoso, bem mobilado, bem cuidado e climatizado. Do ponto de vista clínico, este serviço estava equipado com os meios necessários aos fins a que se propunha (câmara de fluxo laminar, bombas de infusão). O grupo das enfermeiras era empenhado e motivado e era clinicamente liderado por uma enfermeira especializada na área oncológica. A relação entre as enfermeiras e os médicos aparentava ser boa, parecendo partilharem objetivos relativos aos cuidados.

É neste contexto que se deve entender a teoria de médio alcance que passo a apresentar. Esta teoria pretende explicar a relação enfermeira-doente no contexto onde realizei o estudo e caracteriza-se por ser constituída por dois componentes distintos mas complementares: a "natureza da interação" e o "processo de relação".

A "natureza da interação" responde ao primeiro dos objetivos a que me propus (compreender a natureza da interação entre os enfermeiros e os doentes oncológicos submetidos à quimioterapia num hospital-dia), corresponde ao componente expressivo da relação ${ }^{(29)}$ e engloba: o "Processo de avaliação diagnóstica" e o "Processo de intervenção terapêutica de enfermagem".

O "Processo de avaliação diagnóstica", consiste na avaliação/reavaliação da situação do doente/família. Aquela avaliação/reavaliação é feita pelas enfermeiras na conjugação variável da tripla perspectiva: vivencial, de ajuda e biomédica. É na variabilidade da conjugação destas três perspectivas que se constrói a perspectiva de enfermagem. É feita ainda de modo contínuo, sistemático, dinâmico e integrado nos cuidados. Esta definição evidencia ainda que o foco de atenção da enfermeira é o doente e a família. O "Processo de avaliação diagnóstica", para além de muitas outras características, acumula as seguintes duas: ser o timoneiro dos cuidados e consequentemente, estar presente, numa dimensão cronológica, ao longo de todo o processo de prestação de cuidados. Por força destas duas características, adquire especificidade em função da fase da relação na qual ocorre. Tornam-se assim patentes as relações do "Processo de avaliação diagnóstica" com o "Processo de intervenção terapêutica de enfermagem", mas também com o "processo de relação".

Por sua vez, o "Processo de intervenção terapêutica de enfermagem" engloba toda a intervenção com intencionalidade terapêutica da enfermeira, dirigida ao doente e família, bem como à interface destes com o grupo de doentes e a organização. Assim, o foco de atenção da enfermeira pode ser redefinido e afirmar-se que o foco principal é o doente/família, mas é também a interface destes com a organização, os profissionais e o grupo de doentes na sala de quimiote-rapia. Pode-se então afirmar que os cuidados prestados neste contexto têm uma natureza multifocal.

O "Processo de intervenção terapêutica de enfermagem" concretiza-se através de uma razoável diversidade de instrumentos, dos quais destaco: a "gestão de sentimentos" e a "gestão de informação". A "gestão de sentimentos" caracteriza-se, por um lado, pela criação de um espaço-tempo que permita a expressão de sentimentos, e por outro, pela tentativa de promoção da confiança/segurança. A primeira (criação de um espaço-tempo que permita a expressão de sentimentos) é de enorme importância dado que possui potencialidades terapêuticas por si só, e é a base essencial para o desenvolvimento da relação. Existem distintas formas de concessão de espaço-tempo (espaço físico, afetivo, incentivo verbal, não-verbal). No exemplo a seguir estamos perante um incentivo não-
Os clientes e os enfermeiros: construção de uma relação 
verbal (descrito a itálico) e de natureza compreensivo e compassivo da expressão de sentimentos, que ao mesmo tempo denota uma notável disponibilidade interior por parte da enfermeira.

\begin{abstract}
A doente - Ninguém me tinha dito isso. E ele me disse .... mostrou assim uma maneira, como quem diz "olha a franqueza dela, a foiteza". Pronto eu estou aqui para aquilo que Deus quiser. Não me importo e não tenho prazer nenhum da vida (aqui a doente emocionou-se e a sua voz embargou-se), já não vale a pena (a enfermeira agarrou-lhe as mãos com as suas e continuou a olhá-la com uma expressão que denotava atenção e mimetizava os sentimentos da doente). Enfrento a vida .... enfrento a morte como enfrento a vida. $E$ depois disse-lhe "Sr. Dr, eu o que tenho é um câncer". E lá em casa todos sabiam, mas ninguém me queria dizer nada.... (EAA - 070502)
\end{abstract}

Por sua vez a promoção da confiança/segurança surge como resposta à enorme insegurança manifestada pelos doentes e familiares e concretiza-se através do uso de um vasto conjunto de estratégias, das quais destaco: a racionalização; a desmitificação; a não generalização; a explicação dos sintomas; a transmissão de segurança; a antecipação e proposta de soluções; e a oferta de disponibilidade. A título de exemplo reproduzo uma intervenção de uma enfermeira junto do familiar de um doente que se apresentava muito ansioso porque entendia que a quimioterapia já devia ter começado há mais tempo.

Enfermeira - Por isso este tempo todo .... Porque o que é normal, quando a pessoa é operada, mais ou menos no prazo de um mês, deve começar a fazer os tratamentos. Por isso é que ele já está atrasado. Mas também no caso dele é um bocadinho diferente, porque é assim, porque ele teve um curativo que se manteve durante quase um mês, não é? Também foi por causa disso. E enquanto tem ainda a ferida aberta não pode fazer quimioterapia. Está bem? Por isso, muito atrasado não, não pense nisso, porque, por ele ter esse curativo assim, mesmo que tivesse vindo à consulta não podia iniciar os tratamentos. Portanto se calhar estamos na altura certa de começar.... (EAC - 220402)

Através deste exemplo percebe-se também que numa determinada intervenção, a enfermeira não usa apenas uma única estratégia, mas antes uma conjugação de várias. No caso em apreço, percebe-se, por um lado, uma racionalização do processo e por outro, uma desmitificação do atraso no início da quimioterapia.

Também a disponibilidade e a promoção de esperança e da perseverança, assumem um papel importante neste processo. A primeira (a disponibilidade) pode assumir diversas formas, pelo que vou referir apenas algumas. Assim, pode traduzir-se na disponibilização de um contato personalizado, constante e imediato, como no exemplo abaixo.

Enfermeira - (...) A senhora liga para cá ou vem aqui ou passa aqui, eu the dou o meu número de celular, se for preciso alguma coisa, está o número aqui do telefone da unidade. Se eu não estiver, está outra das minhas colegas que sabe informar tal e qual, ....... (EAL1 - 100702)

Ou então na disponibilidade para responder a questões ou dúvidas dos doentes e familiares como no caso que se segue.

Enfermeira - Queria fazer alguma pergunta senhor M.? Tem assim dúvidas, algumas dúvidas ou alguma coisa?... (EAM - 050802)

Relativamente à promoção da esperança, sublinhe-se que a mesma é sinônimo de esperança realista e não necessariamente esperança de cura. A esperança vã não tem lugar no léxico da enfermeira.

O doente - (...) É a vida. Isto pode resultar não é? Isto tem pessoas que .... mas ...

A enfermeira - É perfeitamente natural que o senhor se sinta assim. Mas também tem que acreditar que isto é mesmo assim, que hoje em dia já há tratamentos que ...

O doente - É isso, é isso que eu penso.

A enfermeira - Estes tratamentos, ... pronto, curar, curar, em princípio não ...

O Doente - É difícil.

A esposa - Isso ele sabe.... (EAF - 150702)

A "gestão de informação" deve entender-se em estreita interligação com a gestão de sentimentos. Desenvolve-se de modo informal e de acordo com as necessidades e solicitações do doente e família. À informação é reconhecido um importante papel, pelas características da situação que os doentes estão vivendo. Ou seja, considerando a vivência dos doentes como uma crise ou como uma transição, a informação assume um importante papel na reorganização que permita ultrapassá-las. Assim e para que a informação cumpra o papel de organizador, precisa ser contextualizada, repetida e garantida, às vezes consideradas necessárias pelo doente. O exemplo que a seguir apresento parece-me paradigmático pelo esforço que é colocado na adequação 
da linguagem e pelo pormenor que incide sobre os aspectos que a enfermeira sabe que preocupam o doente.

...Enf ${ }^{a}-(. .)$.$O tratamento é feito como? É feito$ numa veia,... é feito através do sangue. A gente tem que picar uma veia, para depois através dessa veia o medicamento ir a todo o lado, não vai só à barriga, vai a todo o lado. Se houver por aí algumas coisinhas onde quer que seja, o medicamento vai tentar destruí-las. Mas depois, o tipo de tratamento que o senhor vai fazer, é um tratamento que tem que ficar a fazê-lo durante dois dias. E para evitar a internação, esses cateteres, chamam-se cateteres isso que Ihe puseram aí, é como se fosse um .... é uma borrachinha que o senhor tem aí dentro e que está dentro de um dos seus vasos do coração percebe? Portanto nós quando picamos isso,.... isso é para evitar o quê? É para evitar que o senhor fique internado, porque antigamente com esses tratamentos o senhor tinha que ficar aqui internado, com um soro aqui na veia (ao mesmo tempo tocava-lhe no braço) durante dois ou três dias, percebe? Para fazer o tratamento completo. Agora, pondo esses cateteres, que é assim que isso se chama, evita isso. O senhor vai com uma seringazinha.... mas logo depois mostramos-Ihe, ... vai com uma seringa, uma coisa assim pequenina e gordinha (exemplificava o tamanho com as mãos), vai com isso aí dentro do bolso, dentro do bolso da camisa, ou dentro do bolso das calças ou aí dentro (junto ao corpo)... a gente logo depois explica-Ihe. Vai com isso preso com um alfinete e o senhor fica com aquela bombinha, como a gente lhe chama, durante 48 horas, está bem? Que é até amanhã. Amanhã tem que voltar aqui outra vez à da gente, a doutora explicou-lhe como é que era?... (EAV - 220402)

Os instrumentos que acabei de descrever, bem como os cuidados técnico-instrumentais, são usados de modo sistematicamente dinâmico pelas enfermeiras, em função da avaliação que fazem da situação e só podem ser entendidos como um todo. Só o todo permite compreender a especificidade da intervenção da relação enfermeira-doente.

A inter-relação entre os dois construtos atrás referidos ("Processo de avaliação diagnóstica" e "Processo de intervenção terapêutica de enfermagem"), mas também a sua natureza, evidenciam o carácter processual dessa mesma interação. Esse caráter processual, conduz-nos ao segundo componente da teoria de médio alcance: o "processo de relação". Este componente compreende três fases sequenciais: "Princípio da relação", "Corpo da relação" e "Fim da relação". Sendo possível identificar características específicas de cada uma destas fases, é contudo bastante problemático es- tabelecer fronteiras precisas entre elas. De todo o modo, pode-se dizer que a primeira fase ("Princípio da relação") caracteriza-se por começar antes de a enfermeira e o doente se terem encontrado pela primeira vez. Durante este período a enfermeira prepara-se, quer formal quer informalmente, para o encontro com o doente. Porém, o "Princípio da relação" tem o seu momento por excelência durante a entrevista de admissão. Durante esta, constatase que a enfermeira desenvolve predominantemente o "Processo de avaliação diagnóstica", orientado em três direções: o que o doente sabe, o que preocupa o doente e estratégias/capacidades do doente. Mas inicia-se também aqui e quase simultaneamente o "Processo de intervenção terapêutica de enfermagem".

O "Corpo da relação" é constituído pelo essencial do "Processo de intervenção terapêutica de enfermagem". Ou seja, a partir de um conhecimento e confiança que se vão construindo, e guiada por uma reavaliação sistemática da situação, a enfermeira utiliza os instrumentos já atrás identificados (gestão de sentimentos, gestão de informação). É durante esta fase que é desenvolvido o essencial da intervenção terapêutica cujo objetivo é, aprender a viver com a situação com o máximo bem-estar possível.

O "Fim da relação" reúne duas características essenciais: é a fase de fronteira inicial mais indefinida, podendo-se até dizer que está presente desde o início da relação; mas é também a fase de fronteira final mais definida, correspondendo esta ao fim da relação, imposto pelo fim do tratamento ou pela morte do doente. O "Fim da relação" assume características completamente diferentes em função do prognóstico de evolução da saúde do doente. Ou seja, se o prognóstico for considerado bom, o "Fim da relação" assemelha-se a uma celebração e não se vislumbram sinais de luto; se, pelo contrário, se perspectivar um prognóstico mau ou se a relação terminar devido à morte do doente, os sinais de luto e de sofrimento são evidentes, mesmo com caráter antecipatório, surgindo portanto, precocemente na relação. Estas últimas constituem-se como algumas das dificuldades inerentes à relação, na perspectiva das enfermeiras. No entender destas, aquelas dificuldades têm essencialmente a ver com: a vivência da proximidade e do luto e a gestão da agressividade que lhes possa ser dirigida.

\section{DISCUSSÃO DOS RESULTADOS}

Na discussão dos resultados e dadas as limitações próprias de um artigo, limitar-me-ei aos
Os clientes e os enfermeiros: construção de uma relação 
aspectos mais relevantes da natureza da relação. Os relativos ao processo relacional serão futuramente apresentados. Assim e seguindo a mesma ordem, perguntar-se-á, como compreender o "Processo de Avaliação Diagnóstica" no contexto do conhecimento de enfermagem? De acordo com a definição atrás produzida, é indubitavelmente, a forma encontrada pelas enfermeiras que participaram neste estudo para compreenderem a situação dos doentes, de modo a poderem prestar os cuidados respectivos. Nesta acepção, o "Processo de Avaliação Diagnóstica" está de algum modo sobreposto ao conceito de processo de enfermagem. Contudo, e de acordo com os dados, não se pode dizer que este componente diagnóstico seja conduzido sempre, de modo absolutamente consciente e no sentido de atribuir um rótulo diagnóstico a uma determinada situação. Assemelha-se mais ao modo de agir das enfermeiras peritas ${ }^{(13)}$.

A perita, que tem uma enorme experiência, compreende, (...) de maneira intuitiva cada situação e apreende diretamente o problema sem se perder num largo leque de soluções e diagnósticos estéreis ${ }^{(13)}$.

Outros autores ${ }^{(30)}$ assinalam que é menos provável que os enfermeiros peritos usem o processo de enfermagem como um sistema completo, baseando-se mais na intuição e/ou nos julgamentos clínicos baseados na experiência.

Uma outra característica específica do "Processo de Avaliação Diagnóstica" e que se enquadra na perspectiva acima referida ${ }^{(13)}$, é a sua utilização como um instrumento imbuído na ação e dificilmente destrinçável da mesma. Ou seja, tal como já foi referido e exceto num primeiro momento, não existe separação entre um momento de avaliação diagnóstica e um posterior de planejamento e de ação. A avaliação diagnóstica está imbuída nos cuidados, numa relação de tal modo próxima que se torna difícil perceber onde começa e onde acaba. Por outro lado e exceto no primeiro encontro, este instrumento é ao mesmo tempo de avaliação e re-avaliação da situação da pessoa ou da família.

Ao evidenciar estas características, pretendo insinuar que o processo de enfermagem não é utilizado na prática dos cuidados? Não, de todo. Entendo tão só, na linha de pensamento de alguns ${ }^{(11,13,31)}$, que o processo de enfermagem é, em primeira análise, o processo de raciocínio clínico do enfermeiro e que as características do mesmo poderão estar relacionadas com o contexto onde aquele desenvolve a sua prática de cuidados. Por esta ordem de ideias, entendo ainda que o mesmo carece de ser investigado, desvendando-se não só as características do processo, mas também as características do diagnóstico propriamente dito. É também nesse sentido que outros ${ }^{(31)}$ propuseram um sistema que denominaram como "trazendo à superfície o processo de enfermagem". Este consiste basicamente no desenvolvimento de um trabalho indutivo que permita identificar sistematicamente, descrever e analisar a dimensão processual de enfermagem inerente e enraizada na prática quotidiana.

O "Processo de Avaliação Diagnóstica" constitui-se assim como um processo dinâmico e flexível, que permite uma leitura da complexidade da situação do doente e família em contexto, e uma adequação sistemática da resposta da enfermeira. Estas características conferem-lhe centralidade no processo de relação enfermeiro/doente e atribuem-lhe um papel basilar na prossecução dos objetivos terapêuticos, finalidade principal da intervenção desenvolvida pela enfermeira.

O "Processo de intervenção terapêutica de enfermagem", como atrás referi, engloba toda a intervenção com intencionalidade terapêutica da enfermeira. Ao defini-lo deste modo adquire semelhanças com a proposta de $\mathrm{McMahon}^{(32)}$. Este autor propôs quatro áreas que podem ser consideradas terapêuticas, chamando no entanto à atenção para a necessidade de serem investigadas, nomeadamente: relação enfermeiro-doente; intervenções de enfermagem convencionais (intervenções físicas que ajudem a resolver problemas como úlceras de pressão); intervenções de enfermagem não convencionais (práticas das terapias alternativas como a aromaterapia, massagem, cinesiologia). Neste contexto, estou assumindo que o resultado da ação das enfermeiras se traduz em benefícios concretos na saúde das pessoas, entendida esta de uma forma holística e dinâmica e compreendendo o bem-estar, à semelhança das definições propostas por algumas das teóricas de enfermagem ${ }^{(7-8)}$.

Foram realçados mais atrás dois instrumentos usados durante o "Processo de intervenção terapêutica de enfermagem": a "gestão de sentimentos" e a "gestão da informação". O primeiro, é um instrumento usado pelas enfermeiras, cuja utilização é compreensível no contexto da teoria do stress ${ }^{(33)}$, conjugada com a teoria da crise $^{(34)} \mathrm{e}$ com a teoria das relações de objeto ${ }^{(35)}$. Também o conceito de transiçãa ${ }^{(11)}$, é um contributo precioso para a compreensão daquele instrumento. Pode assim entender-se que a relação enfermeira-doente, neste contexto, se constitui como um 
espaço de proximidade, confiança, disponibilidade e continuidade, que permite ao doente reorganizar-se de modo a ultrapassar a crise ou a completar o processo de transição. Para isso contribuem também uma extensa gama de cuidados assumidos pelos enfermeiros, os quais se constituem muitas das vezes como respostas pragmáticas para as dificuldades dos doentes. A "gestão de sentimentos", tal como aqui foi apresentada, denota ainda semelhanças com os resultados de diversos estudos desenvolvidos ${ }^{(36-38)}$.

Por sua vez, a importância atribuída à "gestão da informação" encontra paralelismo no modo como Orem ${ }^{(39)}$ defende a importância da educação do paciente como forma de este se poder autocuidar. Mas também na perspectiva de Roy (Roy \& Andrews $^{(40)}$ ), o qual defende que através da educação do doente, se consegue ajudá-lo a adaptarse ao stress. Neuman ${ }^{(41)}$, por sua vez, destaca o papel da educação em qualquer um dos três componentes do plano de cuidados. Contudo, penso que a proposta de Watson ${ }^{(7)}$ é particularmente interessante dada a aplicabilidade à perspectiva que tenho defendido neste estudo. Aquela autora defende que a educação sobre a saúde é uma das principais funções do enfermeiro e apresenta-a como a função profissional por excelência, através da qual se pode distinguir uma intervenção profissional de uma outra técnica. Todavia, Watson ${ }^{(7)}$ vai mais longe ao propor o "ensino/aprendizagem interpessoal" como um fator maior de cuidado. Neste processo, quer o doente quer a enfermeira alternam papéis de aprendizes e professores no decurso da interação. A enfermeira aprende com o doente a sua história, a sua perspectiva pessoal e estratégias usadas, entre outras, enquanto que o doente recebe da enfermeira elementos de natureza cognitiva e outros que lhe facilitam o lidar com a sua situação. Neste processo, ambos desenvol- vem a sua capacidade de entendimento da situação, bem como os mecanismos para lidarem com a mesma. É curioso lembrar a propósito que as enfermeiras que participaram neste estudo referem que aprenderam com os doentes, por exemplo, a estratégia da centralização sobre o presente. Também Peplau $^{(2)}$ chamou a atenção para o potencial de aprendizagem inerente ao processo de relação enfermeiro-doente, sendo que aquela é essencial para que o doente consiga lidar com a crise associada à doença.

Mas são particularmente relevantes as semelhanças entre a "gestão de informação" e o domínio, "Função de Educação e Guia", proposto por Benner $^{(13)}$, nomeadamente com os seguintes elementos: o momento: saber quando o doente está pronto a aprender; ajudar os doentes a interiorizar as implicações da doença e da cura no seu estilo de vida; saber compreender como o doente interpreta a sua doença; fornecer uma interpretação do estado do doente e dar as razões dos tratamentos; função de guia: tornar abordáveis e compreensíveis os aspectos tradicionalmente tabu de uma doença.

Também o conceito de "educação terapêutica" proposto por Vaughan ${ }^{(42)}$ tem muitas semelhanças com a "gestão da informação". Aquela consiste na atitude da enfermeira de, a partir de uma relação de proximidade, desenvolver um processo de ensino dirigido especificamente às necessidades do doente. Este não passa pelas abordagens didáticas tradicionais, mas antes por uma atitude afetivamente envolvida e comprometida e dirigida ao aproveitamento e desenvolvimento das potencialidades do doente. A autora entende que esta abordagem tem elevado potencial terapêutico, com repercussões na gestão do stress, na qualidade de vida e no desenvolvimento pessoal.

\section{REFERÊNCIAS}

(1) Heron J. Helping the client. A creative practical guide. $5^{\text {th }}$ ed. London: Sage; 2001.

(2) Peplau HE. Relaciones interpersonales en enfermería. Barcelona: Salvat; 1990.

(3) Orlando I. The dynamics nurse-patient relationship. New York: G. P. Putnam’s; 1961.

(4) Travelbee J. Interpersonal aspects of nursing. $2^{\text {nd }}$ ed. Philadelphia: F.A. Davis; 1971.

(5) Kérouac S, Pepin J, Ducharme F, Duquette A, Major F. La pensée infirmière. Conceptions e stratégies. Québec: Éditions Études Vivantes; 1994.
(6) Lopes MJ. Concepções de enfermagem e desenvolvimento sócio-moral. Alguns dados e implicações. Lisboa: Associação Portuguesa de Enfermeiros; 1999.

(7) Watson J. Nursing: the philosophy and science of caring. Buolder: Colorado Associated University Press; 1985.

(8) Parse RR. Human becoming: Parse's theory of nursing. Nurs Sci Q 1992; 5:35-42.

(9) Lazure H. Viver a relação de ajuda. Lisboa: Lusodidacta; 1994.
Os clientes e os enfermeiros:

construção de uma relação 
(10) Chalifour J. La relation d'aide en soins infirmiers: une perspective holistique-humaniste. Paris, Editions Lamarre; 1989.

(11) Meleis AI. Theoretical nursing: development \& progress. $3^{\text {rd }}$ ed. Philadelphia: J.B. Lippincott; 1997.

(12) Aguilera DC. Crisis intervention. Theory and methodology. $8^{\text {th }}$ ed. Saint Louis: Mosby; 1998.

(13) Benner P. De iniciado a perito. Coimbra: Quarteto; 2001 .

(14) Easter A. Construct analysis of four modes of being present. J Holist Nurs 2000; 18(4):362-77.

(15) Schön DA. A la recherche d'une nouvelle épistemologie de la pratique et de ce qu'elle implique pour l'éducation des adultes. In: Barbier JM, organizateur. Savoirs théoriques et savoirs d'action. $2^{\mathrm{e}}$ edition. Paris: Presses Universitaires de France; 1998.

(16) Altet M. Análise das práticas dos professores e das situações pedagógicas. Porto: Porto; 2000.

(17) MacIntyre A. After virtue. $2^{\text {nd }}$ ed. Notre Dame: University of Notre Dame Press; 1990.

(18) Chinn PL, Kramer MK. Theory and nursing. Integrated knowledge and development. $5^{\text {th }}$ ed. Saint Louis: Mosby; 1999.

(19) Morse JM, Swanson JM, Kuzel AJ. The nature of qualitative evidence. London: Sage; 2001.

(20) Míguelez MM. Criterios para la superación del debate metodológico "cuantitativo/cualitativo". Rev Interam Psicol 2001; 33(1):79-107.

(21) Olabuénaga JIR. Metodología de la investigación cualitativa. $2^{\text {a }}$ ed. Bilbao: Universidad de Deusto; 1999.

(22) Strauss AL, Corbin J. Basics of qualitative research: techniques and procedures for developing grounded theory. $2^{\text {nd }}$ ed. Sage; 1998.

(23) Lopes MJ. A metodologia da grounded theory: um contributo para a conceitualização na enfermagem. Rev Invest Enferm 2003; 8:63-74.

(24) Flick U. An introduction to qualitative research London: Sage; 1998.

(25) Morgan DL. Focus groups as a qualitative research. Newbury Park, CA: Sage; 1988.

(26) Goffman E. A apresentação do eu na vida de todos os dias. Lisboa: Relógio d'Água; 1999.
(27) Evertson C, Green J. Observation as inquiry and method. In: Wittrock MS. Handbook of research on teaching. New York: Macmillan; 1986.

(28) Morse JM, Swanson JM, Kuzel A.J. The nature of qualitative evidence. London: Sage; 2001.

(29) Basto ML. Da intenção de mudar à mudança. Um caso de intervenção num grupo de enfermeiras. Lisboa: Rei dos Livros; 1998

(30) Fonteyn ME, Cooper LF. The written nursing process is it still useful to nursing education? J Adv Nurs 1994; 19:315-9.

(31) Chenitz WC, Swanson JM. Surfacing nursing process, a method for generating nursing theory from practice. J Adv Nurs 1984; 9:205-15.

(32) McMahon R, Pearson A, organizer. Nursing as the-rapy. London: Chapman \& Hall; 1991.

(33) Lazarus RS. Personalidade e adaptação. $5^{\mathrm{a}}$ ed. Rio de Janeiro: Zahar; 1979.

(34) Caplan G. Princípios de psiquiatria preventiva. Rio de Janeiro: Zahar; 1980.

(35) Balint M. A falha básica. Aspectos terapêuticos da regressão. Porto Alegre: Artes Médicas; 1993.

(36) Swanson K. Empirical development of middle range theory of caring. Nurs Res 1991; 40(3):1616.

(37) Ersser S. 'Nursing beds and nursing therapy'. In: Pearson A, editor. - Primary nursing: nursing in the Burford and Oxford Nursing Developments Units, Crom, Helm. London: 1988.

(38) Motyka M, Motyka H, Wsolek. R. Elements of psychological support in nursing care. J Adv Nurs 1997; 26(5):909-12.

(39) Orem DE. Soins infirmiers: les concepts et la pratique. Montréal: Décarie; 1987.

(40) Roy C, Andrews HA. Teoria da enfermagem: o modelo de adaptação de Roy. Lisboa: Instituto Piaget; 2001.

(41)Neuman B. The Neuman systems model. Application to nursing education and practice. Norwalk: CT: Appleton-Century-Crofts; 1982.

(42) Vaughan B. Patient education in therapeutic nursing. In: McMahon R, Pearson A, organizer. Nursing as therapy. London: Chapman \& Hall; 1991. 